\title{
DEVELOPMENT OF RECIPROCATING TRIBOMETER FOR TESTING SYNOVIAL JOINT
}

\author{
P. Č́́pek ${ }^{*}$, D. Rebenda, D. Nečas, M. Vrbka, I. Křupka
}

\begin{abstract}
The painless movement is very important in active life; therefore, the right function of our synovial joints is necessary. The synovial joints can be injured during human life in several ways. When the synovial joint is too damaged, change for the artificial joint follows. The artificial joint does not have long lifetime; therefore, the operation of the damaged joint is usually postponed by medical treatments (viscosuplementation). Scientists have to understand lubrication and wear processes to postpone the operation of the artificial joint. There are too many unanswered questions in this field. However, recently this field of science is becoming very popular and the number of publications is increasing. This article is a presentation of a new tribometer for research in biotribologic field. The new tribometer will allow us to do research on lubrication of the human joint cartilage. We will be able to observe the cartilage-on-glass contact and visualize the lubrication film. We will also be able to measure friction coefficient during the experiments. This conception of tribometer does not exist among conventional suppliers.
\end{abstract}

Keywords: biotribology, cartilage, friction, synovial fluid, reciprocating tribometer

\section{Introduction}

Synovial joint consists of two bones whose surfaces of cartilage are located opposite to each other. Cartilage is heterogeneous material with low cell density (Quinn et al., 2005) and it is formed by 80 $90 \%$ of water. Surface of cartilage is lubricated by synovial fluid. Hyaluronic acid is the main part of synovial fluid contributing to the lubrication of cartilage (Radin et al., 1970). The most important for lubrication of cartilage is its porous structure. The cartilage pores work like a stack of lubricant. The natural synovial joint can be injured and damaged. However, the artificial joint does not exhibit unlimited lifetime, therefore there is a general effort to prevent necessity of implantation of artificial joint.

Stachowiak et al. (1994) used pin-on-disk tribometer with reciprocating motion. Pin was made from cartilage and disk was made from stainless steel. Load was realized by lever and pulley system. Tribometer with swinging reciprocating motion was used in McCanna's article (2008). Friction samples were made from cartilage or stainless steel. Simulator had static tibial part, where stationary contact specimens were situated. Swinging motion was realized by an arm. The pin-on-plate configuration of tribometer was used by Moore, et al. (2016). The contact was realized by a glass plate and a cartilage pin. Glass plate was mounted to a carriage. This subassembly was fitted to linear rods allowing move in reciprocating way. Actuator drived a ball screw which moved the carriage. Cartilage sample was placed in a sample clamp on 6-axis load cell and under the load cell was located the loading system.

The visualization of the contact area is desirable for the clarification of phenomena which undergoes in cartilage during motion. In this case, there is a lack of knowledge, because most studies focus only on friction measurements. One possible way, how to achieve contact visualization is using one of the optical methods. Optical methods are at advanced level in our department, therefore we can observe the contact area in situ but any reciprocating tribometer for observation of cartilage surfaces does not exist so far.

Ing. Pavel Čípek.: Institute of Machine and Industral Design, Brno University of Technology, Technická 2896/2; 616 69, Brno; CZ, Pavel.Cipek@vut.cz 


\section{Reciprocating tribometer}

Our experimental activities require us to design reciprocating tribometer, because this concept is missing yet. Observation of the contact area is necessary to better understand the lubrication mechanisms. Measurement of friction and loading forces are required too. Concepts of tribometers, which authors were used in above references, were taken as an inspiration for a possible design of new tribometer. Only the suitable segments from particular concepts were used. The pin-on-plate configuration was chosen. Sample of cartilage will be placed below the plate. Plate will be made from optical glass. Contact area will be flooded by synovial fluid.

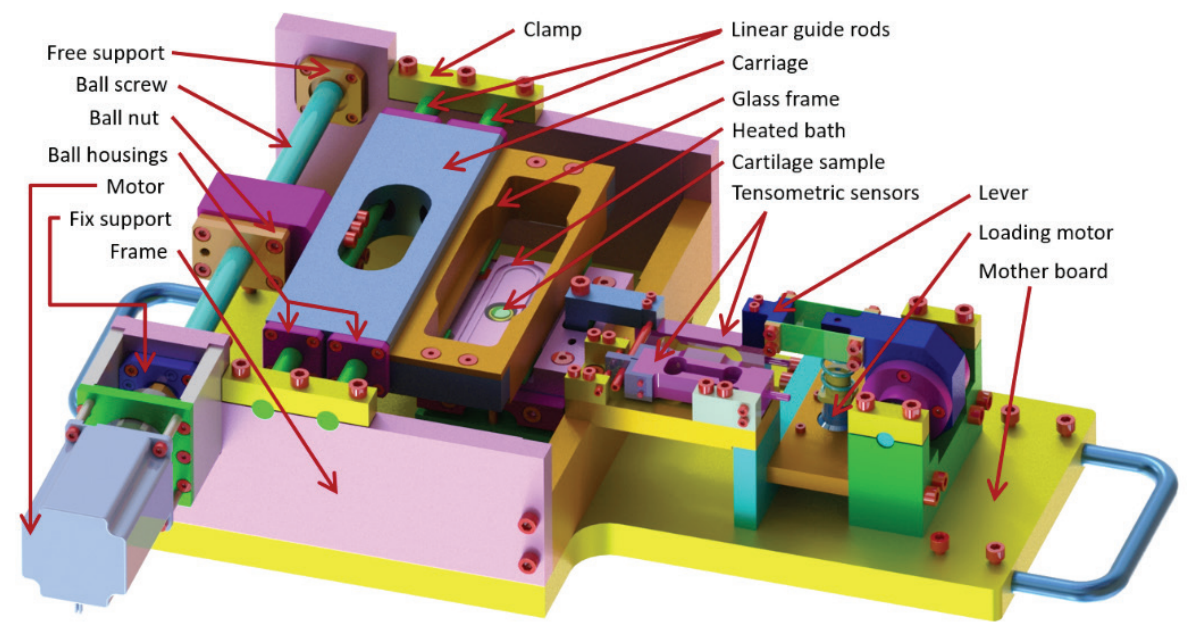

Fig. 1: New tribometer assembly

The new concept of reciprocating tribometer is shown in Fig. 1. The frame provides a strong support for whole structure. The frame is mounted on a motherboard. The lever secures clamping of sample and load. The load is applied by very accurate linear stepper motor via the spring. The lever is mounted to a bearing housing, which allows movement around one axis. The bearings in their housing are preloaded in a shaft with $\mathrm{KM}$ nut and MB washer. The lever is mounted to the frame by the bearing shaft. The lever also contains deformation elements that allow deformation of stiff lever in one required location. The tensometric sensors allow monitoring of loading and measurement of friction forces. The first sensor is part of the lever and the second sensor is connected in parallel with the lever. Part of the lever at the contact area is sunk into the heated bath with synovial fluid. The sample is clamped to the end of the lever. The bath consists of two main parts, upper and lower part. There are two holes for heating patrons and one hole for a thermocouple in the lower part. There is X-ring in the upper part which seals the contact area and prevents leakage of the fluid. The bath is mounted to the frame on rail, that secures the right position of bath. X- ring is the seal between the bath and the optical glass. The optical glass is fixed to a glass frame that is part of the moving carriage. The carriage can move in one axis and it is able to conduct a reciprocating motion. Two linear rods allow this type of movement. These linear rods are fixed to the frame by two clamps. The carriage is fitted on linear rods by ball housings on each side together by four housings. Both linear guide rods are located on one side of the carriage and there is connected drive on the same side. Linear motion is mediated by ball screw. Housing for a ball screw nut creates a part of the carriage. Ball screw is mounted to ball bearing housings on both sides. The first, main supports allows only rotation around one axis and other motion is impossible. This support is installed on the motor side. Second support allows one direction translation and rotation around one axis. Rotational motion is secured by stepper motor.

\section{Control system}

The control system is based on Arduino. This system controls stepper motor and its reciprocating and loading motion. These stepper motors are not directly connected to Arduino, but they are connected via drivers. All motors have their own driver and power supply. Scheme of the whole system is shown in Fig. 2. There are two main parts of this control system. First part is the movement part, which consists of motor, driver and power supply. The motor secures the reciprocating movement of the carriage. Driver receives the control signals from Arduino. The second interesting part of control system is the loading 
control system. This part of the control system allows movement of the lever. It consists of the driver, the stepper linear motor and the power supply. Its function has the same principle.

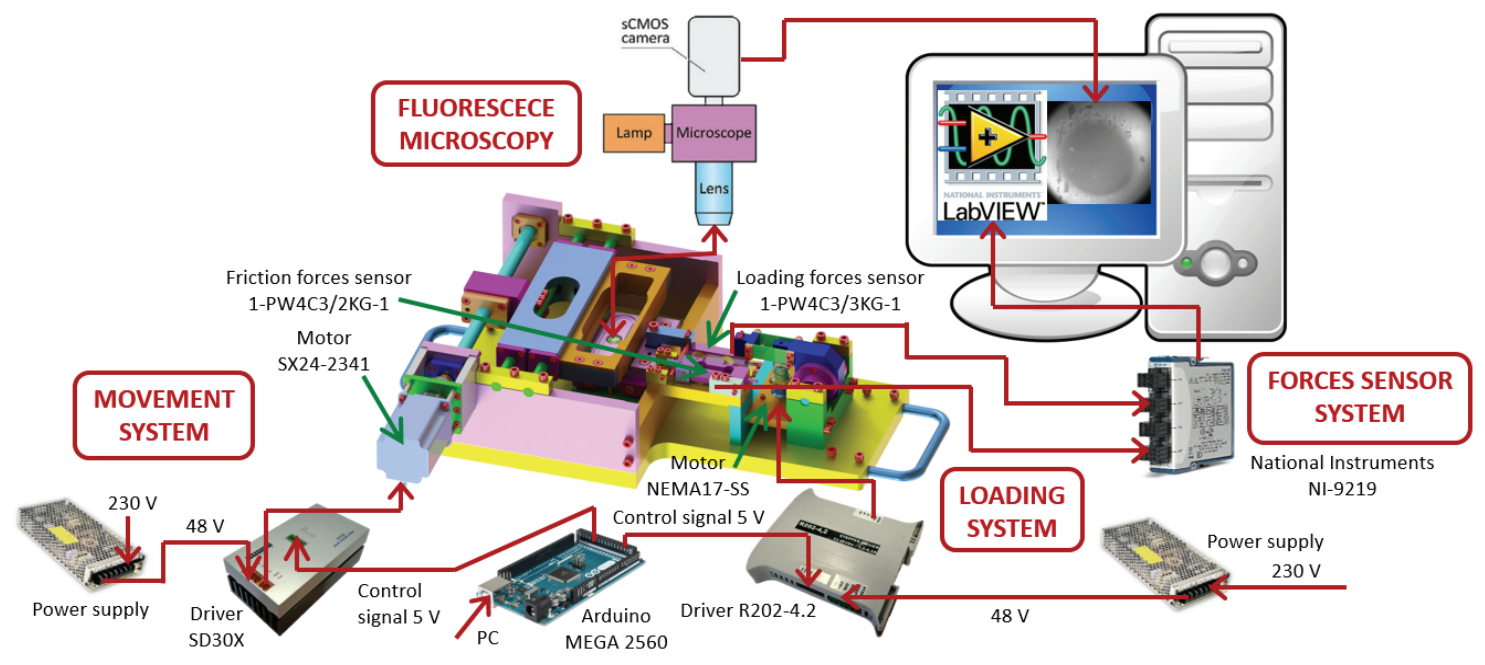

Fig. 2: Scheme of the control and measuring system

\section{Measuring system}

The measuring system is created by combination of force measurement system and optical method, particularly fluorescence microscopy. First subsystem consists of two tensometric sensors and a measuring card NI 9219. The measuring card is connected to PC and signal from sensors is recorded by LabVIEW. The friction tensometric sensor has maximum capacity of $2 \mathrm{~kg}$ and minimum verification interval of $0.2 \mathrm{~g}$. The second loading tensometric sensor has maximum capacity of $3 \mathrm{~kg}$ and minimum verification interval of $0.5 \mathrm{~kg}$. The fluorescence microscopy is an interesting part of the measuring system. Lubricant, or some lubricant components, have to be fluorescently marked. These marked parts of the lubricant are emitting light when they are stimulated by monochromatic light. Intensity of the emitted light is measured and observed. We are able to mark only individual components of the lubricant and observe their behavior in the contact area. This method allows visualization of the contact. It has been already used in our workplace (Nečas et al., 2015, 2016; Košt'ál et al., 2015). Scheme of complete measuring system is shown in Fig. 2.

\section{Samples and experiment conditions}

The samples were taken from animal cartilage as soon as possible after animal donor sacrifice. Pin samples were taken from a pig hip joint by hollow drill bit. These samples have diameter of $5.7 \mathrm{~mm}$ or $9.7 \mathrm{~mm}$. The samples were frozen in PBS at $-20^{\circ} \mathrm{C}$ after sampling. This practice is correct and verified by Shi et al. (2011), Blum and Ovaert (2013), Cilingir (2015). The samples were unfrozen immediately before experiments. The chosen experiment conditions were based on previous publications and conditions in human synovial joint. The experimental loads will be $1-10 \mathrm{~N}$ and sliding speed will be 3-10 mm/s (Stachowiak, 1994; McCanna, 2008; Moore, 2016). The bath around the contact area will be heated to the temperature of a human body.
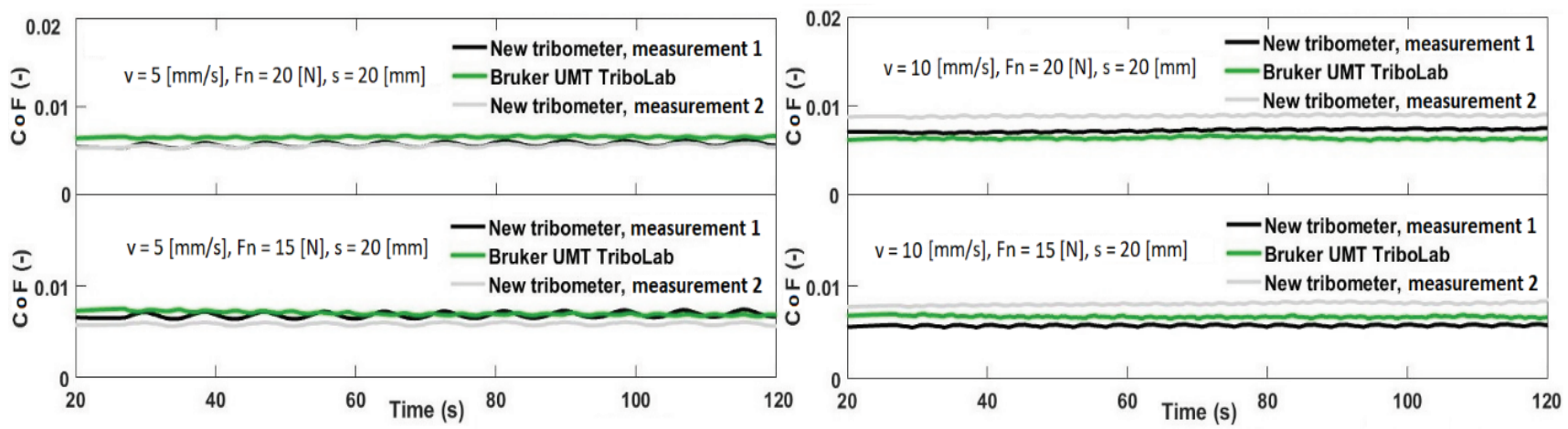

Fig. 3: Results from verification measurements 


\section{Results}

Verification experiments were realized. Pin material for experiments was used PTFE G400 and as lubricant was used PBS. Experimental conditions are given in labels in the Fig. 3. Temperature during the experiments was $20{ }^{\circ} \mathrm{C}$. The comparative experiments were realized on Bruker UMT TriboLab with the same conditions. The experiment results from both devices were compared and are shown in Fig. 3. Curve trends are the same. The deviation and repeatability of measurements is around $20 \%$.

\section{Conclusions}

The reciprocating tribometer for testing natural cartilage was designed and manufactured. Devices with this possibility haven't been available at our department before. The new concept meets all the requirements. This concept will allow measuring of force effect and at the same time we will be able to visualize contact between the cartilage tissue and the optical glass by optical methods. Measuring system of this device was calibrated and verificated using Bruker UMT TriboLab. Acquired results show good comparability with comercial device. The new concept of tribometer proved to be suitable for testing synovial joints. Photo of the new tribometer is shown in Fig. 4.
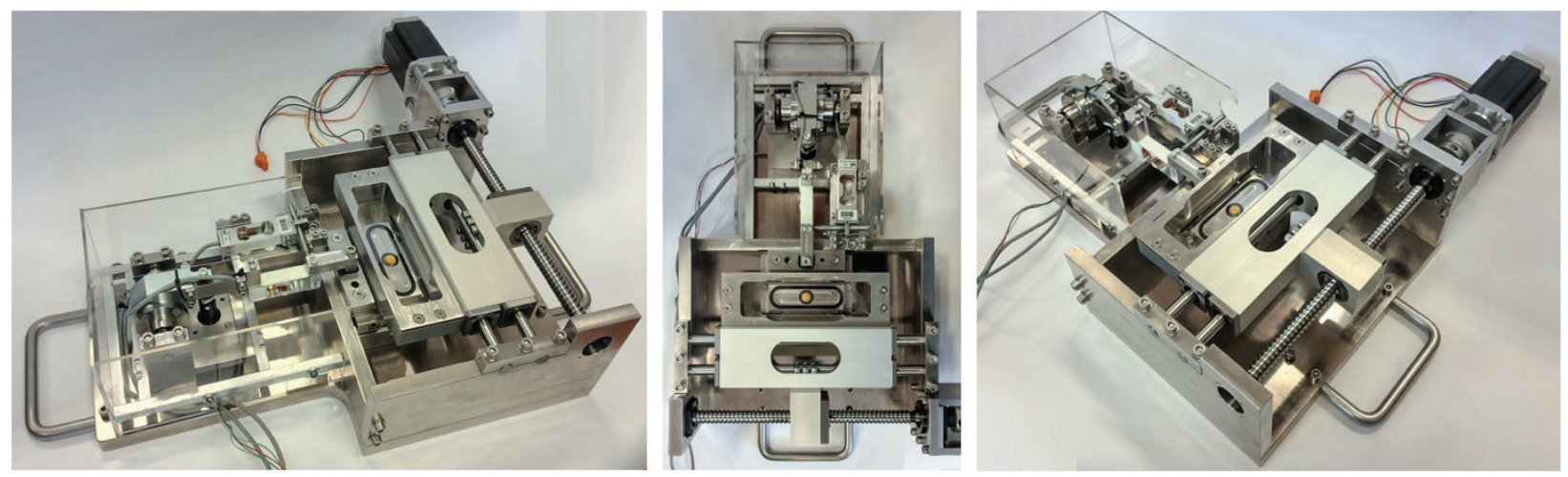

Fig. 4: New reciprocating tribometer

\section{Acknowledgement}

This research was carried out under the project LTAUSA17150 with financial support from the Ministry of Education, Youth and Sports of the Czech Republic.

\section{References}

Blum, M. M., Ovaert, T. C., (2013) Investigation of friction and surface degradation of innovative boundary lubricant functionalized hydrogel material for use as artificial articular cartilage. Wear, 301, 1-2, pp. 201-209.

Cilingir, A. C., (2015) Effect of Rotational and Sliding Motions on Friction and Degeneration of Articular Cartilage under Dry and Wet Friction. Journal of Bionic Engineering, 12, 3, pp. 464-472.

Kostal, D., et. al., (2015) Lubricant rupture ratio at elastohydrodynamically lubricated contact outlet. Tribology Letters, 59, 3, pp. 39.

Mccann, L., et. al., (2008) Tribological testing of articular cartilage of the medial compartment of the knee using a friction simulator. Tribology International, 41, 11, pp. 1126-1133.

Necas, D., et. al., (2015) Film thickness mapping in lubricated contacts using fluorescence.

Necas, D., et. al., (2016) Lubrication within hip replacements-Implication for ceramic-on-hard bearing couples. Journal of the mechanical behavior of biomedical materials, 61, pp. 371-383.

Quinn, T. M., Hunziker, E. B., Häuselmann, H. (2005) Variation of cell and matrix morphologies in articular cartilage among locations in the adult human knee. Osteoarthritis and Cartilage, 13, 8, pp. 672-678.

Radin, E., L., Swann, D., A., Weisser, P., A., (1970) Separation of a Hyaluronate-free Lubricating Fraction from Synovial Fluid. Nature, 228, 5269, pp. 377.

Shi, L., et. al., (2011) Experimental Friction Coefficients for Bovine Cartilage Measured with a Pin-on-Disk Tribometer: Testing Configuration and Lubricant Effects. Annals of Biomedical Engineering, 39, 1, pp. 132-146.

Stachowiak, G. W., Batchelor, A. W. and Griffiths, L. J. (1994) Friction and wear changes in synovial joints. Wear, 171, 1, pp. 135-142. 